Article

\title{
High Purity and Low Molecular Weight Lignin Nano-Particles Extracted from Acid-Assisted MIBK Pretreatment
}

\author{
Qilin Zhang ${ }^{1,2} \mathbb{D}$, Haichao Li ${ }^{1,2}$, Zongwei Guo ${ }^{1,2}$ and Feng $\mathrm{Xu}^{1,2, *}$ \\ 1 Beijing Key Laboratory of Lignocellulosic Chemistry, Beijing Forestry University, Beijing 100083, China; \\ zq191824@bjfu.edu.cn (Q.Z.); lihaichao96@bjfu.edu.cn (H.L.); guozongwei@bjfu.edu.cn (Z.G.) \\ 2 MOE Key Laboratory of Wooden Material Science and Application, Beijing Forestry University, \\ Beijing 100083, China \\ * Correspondence: xfx315@bjfu.edu.cn; Tel./Fax: +86-10-62337993
}

Received: 15 November 2019; Accepted: 27 January 2020; Published: 8 February 2020

\begin{abstract}
A simple and economical biorefinery method, organosolv methyl isobutyl ketone (MIBK) pretreatment assisted by Lewis acid ferric trichloride hydrolysis, was proposed for fractionating the lignin from extractive-free Eucalyptus powder at the nanoscale, accompanied by another product furfural, derived from hemicellulose. Under the conditions $\left(180{ }^{\circ} \mathrm{C}, 1 \mathrm{~h}\right)$ optimized based on the best yield of furfural, $40.13 \%$ of the acid-insoluble lignin (AIL) could be obtained with a high purity of $100 \%$, a low molecular weight of $767\left(M_{n}\right)$ and improved thermostability. The extracted lignin was characterized by its chemical structure, thermostability, homogeneity, molecular weight, and morphology as compared with milled wood lignin (MWL). The results showed significant variations in chemical structures of the extracted lignin during the pretreatment. Specifically, the aryl ether linkage and phenylcoumarans were broken severely while the resinols were more resistant. The G-type lignin was more sensitive to degradation than the S-type, and after the pretreatment, H-type lignin was formed, indicating the occurrence of a demethoxylation reaction at high temperature. Moreover, the lignin nano-particles were identified visually by AFM and TEM images. The dynamic light scattering (DLS) showed that the average diameter of the measured samples was $131.8 \mathrm{~nm}$, with the polydispersity index (PDI) of 0.149. The MIBK-lignin nano-particles prepared in our laboratory exhibit high potentials in producing high functional and valuable materials for the application in wide fields.
\end{abstract}

Keywords: lignin nano-particles; organosolv pretreatment; Eucalyptus wood; biomass; biorefinery

\section{Introduction}

Due to abundant greenhouse gas and severe environmental problems caused by fossil fuels and the limited non-renewable energy, the pathway of valorizing the renewable lignocellulosic biomass for materials, chemicals, and biofuels has attracted many interests in recent decades [1,2]. Lignocellulose is mainly composed of cellulose, hemicellulose, and lignin. Specifically, cellulose and hemicellulose are classes of polymers containing one or several monosaccharide units. Especially for cellulose, a component of biomass in yielding specialty chemicals and functional materials as a result of the simple chemical composition and crystalline structure [3]. However, cellulose is well protected by the surrounding biomass recalcitrance, a barrier structured by hemicellulose and lignin. Lignin is the main factor hindering the cellulose valorization; however, on the other hand, it is also one of the few natural large-scale sources of aromatic compounds [4]. Three types of methoxylated phenylpropanoid units including $p$-hydroxyphenyl $(\mathrm{H})$, guaiacyl $(\mathrm{G})$, and syringyl $(\mathrm{S})$ coupled by aryl ether $(\alpha-\mathrm{O}-4$, $\beta-O-4$, and $4-O-5)$ or carbon-carbon linkage $(\beta-\beta, \beta-1, \beta-5$, and $5-5)$ construct such complex lignin 
architecture [5,6]. Abundant aromatic functional groups make it useful for renewable chemicals or functional materials [7-9]. Therefore, an effective pretreatment to fractionate lignin, cellulose, and even hemicellulose from lignocellulosic biomass will facilitate economic biorefinery.

Some common pretreatments have been proved effective in breaking the biomass recalcitrance using sulfuric acid, sodium hydroxide, organosolv, ionic liquids, and deep eutectic solvents, etc. [10-13]. Due to the diseconomy and pollution caused by the effluent from acid and alkali pretreatment, organosolv pretreatment, based on the principle of dissolving lignin by certain organic solvents, presents a promising alternative $[14,15]$. $\mathrm{EtOH}$ and $\mathrm{MeOH}$ are the common solvents applied in organosolv pretreatment for economic reasons, although a number of organosolv have been developed, including ketones, esters, phenols, and high boiling alcohols $[15,16]$. Generally, the organosolv pretreatments incubate biomass with plenty of organic or aqueous-organic solvents at $150-200{ }^{\circ} \mathrm{C}$ catalyzed by acids such as sulfuric acid, formic acid, etc. [15,17,18] El Hage et al. [19] studied the lignin extraction by ethanol organosolv pretreatment at $190{ }^{\circ} \mathrm{C}$ for $60 \mathrm{~min}$, and the results showed that the $\beta-O-4$ linkages and ester bonds were mainly cleaved; however, the core of the lignin structure did not show any significant change. Although the lignin extracted by organosolv pretreatments generally shows a number of advantages, including high purity, low molecular weight, and sulfur-free process [20]; however, the poor yield of the lignin fraction and the less effect on hemicellulose still block the downstream biorefinery process. A two-step procedure combined with dilute-acid soakage with an aqueous-ethanol organosolv treatment was proposed by Brosse et al. [18]. The yield of ethanol organosolv lignin was improved remarkably, reaching $71 \%$. Moreover, $73 \%$ of xylose from the raw material was recovered, which indicated that the removal of hemicellulose also potentially benefited the organosolv treatment for lignin. To simplify such a two-step treatment, the aqueous-ethanol organosolv was modified by adding the hydrophobic organosolv, methyl isobutyl ketone (MIBK), resulting in the ternary mixture divided into two phases. Hence, the hemicellulose degradation occurred in the aqueous phase, while the organic solvent dissolved the lignin constantly [21,22]. Bozell et al. [16] proposed a new organosolv pretreatment process for fractionating lignocellulosic material into cellulose, hemicellulose, and lignin using a ternary mixture of MIBK, ethanol, and water with a sulfuric acid concentration of more than $0.1 \mathrm{M}$. The results showed that more than $95 \%$ of the lignin and hemicellulose was removed from the raw materials, giving a high content of cellulose, approaching $98 \%$ after clean fractionation process. However, it is still unsatisfactory in the recovery of the hemicellulose and lignin. Although current studies on pretreatment systems for removing lignin or breaking the biomass recalcitrance has focused on the ionic liquids (ILs) [23-27] and deep eutectic solvents (DESs) pretreatments [28-32], the challenge of the cellulose valorization without compromises of lignin and hemicellulose fractions is still unresolved.

In this work, a simple and economical pretreatment method is proposed for good valorization of both lignin and hemicellulose. The organosolv pretreatment on extractives-free Eucalyptus sample was modified by adding the Lewis acid, ferric trichloride solution, aiming at good degradation of the hemicellulose in the aqueous phase, simultaneously facilitating the lignin dissolution by MIBK. Additionally, this biphasic system is also advantageous in producing furfural, a valuable platform chemical derived from hemicellulose. Hence, the conditions were optimized based on the maximum yield of furfural to preferentially make full use of the hemicellulose and the lignin was isolated from the MIBK phase. To investigate the chemical structure conversions of the extracted MIBK-lignin during the pretreatment, milled wood lignin (MWL) was prepared for a control, and characterization methods such as solution-state two-dimensional heteronuclear single-quantum coherence NMR (2DHSQC NMR) spectroscopy, gel permeation chromatography (GPC), atomic force microscopy (AFM), and Fourier transform infrared spectroscopy (FTIR), etc. were applied. This pretreatment method provides a potential for both the lignin and hemicellulose valorization. 


\section{Materials and Methods}

\subsection{Materials}

Methyl isobutyl ketone (MIBK) was purchased from Macklin (Shanghai, China). Iron chloride hexahydrate was provided by Aladdin (Shanghai, China). All the chemicals were of analytical grade and used without further purification. Eucalyptus slices were collected by Sunpaper Industry Joint-Stock Co., Ltd. (Jining, China). The Eucalyptus slices were ground by an FZ120 plant shredder (Truelab, Shanghai, China). Then the Eucalyptus powder was extracted with toluene/ethanol (2:1, v/v) in a Blst-250SQ Soxhlet apparatus (Bilon, Shanghai, China) for $12 \mathrm{~h}$, and air-dried for $24 \mathrm{~h}$ for further use.

\subsection{Isolation of MIBK-Lignin}

The isolation of MIBK-lignin was carried out in a 304 stainless steel batch reactor with a $50 \mathrm{~mL}$ capacity polyphenylene lining (Zhengzhou Boke instrument equipment Co., Ltd., Zhengzhou China). The Eucalyptus sample $\left(0.4 \mathrm{~g}\right.$ ) was soaked in $4 \mathrm{~mL}$, and $0.06 \mathrm{~mol} / \mathrm{L}$ of $\mathrm{FeCl}_{3}$ solution and then was added $16 \mathrm{~mL}$ of MIBK. The reactor was heated to $180{ }^{\circ} \mathrm{C}$ with an average heating rate of $2{ }^{\circ} \mathrm{C} / \mathrm{min}$ and kept for $1 \mathrm{~h}$. Then the reaction was stopped by the tap water to cool down to the room temperature immediately. The upper phase MIBK was collected, followed by the rotary evaporation. The ethanol (40 mL) was added to the concentrated lignin MIBK solution for better dispersion, then dropped in distilled water $(500 \mathrm{~mL})$ to precipitate the lignin. Finally, the MIBK-lignin sample was obtained by filtration, using a filter membrane with $0.22 \mu \mathrm{m}$ pore diameters and then freeze-dried for $48 \mathrm{~h}$.

\subsection{Isolation of Milled Wood Lignin (MWL)}

The MWL from Eucalyptus was obtained by ball-milling for $12 \mathrm{~h}$ with a speed of $450 \mathrm{rpm}$, then extracted with 1,4-dioxane for $48 \mathrm{~h}$, according to the modified Björkman's method [5].

\subsection{Chemical Composition of MIBK-Lignin}

The chemical composition of MIBK-lignin was analyzed according to the National Renewable Energy Laboratory (NREL) methods [33]. The yield and purity of MIBK-lignin were calculated based on the acid-insoluble lignin in the biomass.

\subsection{D-HSQC NMR Analysis}

The lignin sample (40 mg) was dissolved in $0.5 \mathrm{~mL}$ of DMSO- $d_{6}$ and analyzed by NMR (Bruker Advance $400 \mathrm{MHz}$ instrument, Karlsruhe, Germany) with a $5 \mathrm{~mm}$ gradient probe at room temperature.

\subsection{FT-IR Spectroscopy Analysis}

The lignin sample was analyzed by Tensor II FT-IR spectroscopy (Bruker, Karlsruhe, Germany) at room temperature. The lignin sample was pelleted with $\mathrm{KBr}$. The number of scans were 128 for each sample, and the distinguishability was $4 \mathrm{~cm}^{-1}$ over the range of 3800 to $800 \mathrm{~cm}^{-1}$ in the transmission mode.

\subsection{Gel Permeation Chromatograph (GPC) Analysis}

The weight-average $\left(M_{\mathrm{w}}\right)$ and number-average $\left(M_{\mathrm{n}}\right)$ of lignin sample were detected by Agilent 1200 gel permeation chromatography (Agilent, Santa Clara, CA, USA) equipped with a refraction index detector (RID) and a PL-gel Mixed-B column (300 mm $\times 7.5 \mathrm{~mm})$. The mobile phase was tetrahydrofuran (THF) with the flow rate of $1 \mathrm{~mL} / \mathrm{min}$. The column and detector temperature were set as $40^{\circ} \mathrm{C}$. 


\subsection{Thermogravimetric Analysis}

The thermogravimetric analysis (TGA) of the lignin sample was determined by the thermal analyzer (SDT Q600, TA Instrument, New Castle, DE, USA). The sample $(5 \mathrm{mg})$ was placed in an $\mathrm{Al}_{2} \mathrm{O}_{3}$ crucible $(70 \mu \mathrm{L})$ heating rate of $10^{\circ} \mathrm{C} / \mathrm{min}$ from 25 to $550{ }^{\circ} \mathrm{C}$ under a nitrogen atmosphere with a flow rate of $50 \mathrm{~mL} / \mathrm{min}$.

\subsection{Atomic Force Microscopy (AFM) Images}

The acquired MIBK-lignin was dispersed in deionized water at a concentration of $0.2 \mathrm{~g} / \mathrm{L}$ followed by ten-minute ultrasound treatment. The upper suspension liquid was dropped on the clean mica surface then air-dried. The morphology of the MIBK-lignin sample was observed by Atomic force microscopy (Bruker Multimode 8 instrument, Karlsruhe, Germany).

\subsection{Transmission Electron Microscopy (TEM) Images}

The acquired MIBK-lignin was dispersed in deionized water with ten-minute ultrasound treatment. The upper suspension liquid was dropped on the carbon-coated copper grid and air-dried overnight. The sample was observed by JEM-1010 TEM (JEOL, Tokyo, Japan).

\subsection{Dynamic Light Scattering (DLS) Analysis}

The lignin nano-particle diameters were analyzed by Nano-ZS90 (Malvern, UK). The sample was dispersed in deionized water with ten-minute ultrasound treatment, and the upper suspension liquid was collected for measurements.

\section{Results and Discussion}

\subsection{Purity and Molecular Weight Distributions}

MIBK-lignin was compared with MWL in yield, purity, and molecular weight illustrated in Table 1. Due to the mild extraction conditions (room temperature), MWL yield is commonly below $20 \%$ based on the lignin existed in the original biomass, and in this work, the MWL yield from Eucalyptus was $8.53 \%$. However, our MIBK-lignin was isolated under pretty high temperature $\left(180^{\circ} \mathrm{C}\right)$. Simultaneously, the hemicellulose was degraded significantly under a weakly acidic system, which facilitated the lignin extraction. Moreover, the organic solvent MIBK can prevent the polysaccharide from extracting into the organic phase due to poor solubility. Hence, the MIBK-lignin was obtained with a competitive yield $(40.31 \%)$ and a unique high purity $(100 \%)$.

Table 1. The yields, purity, molecular weight, and polydispersity index (PDI) from MWL and MIBK-lignin.

\begin{tabular}{cccccc}
\hline Component & Yield $^{\mathbf{a}} \mathbf{( \% )}$ & Purity $^{\mathbf{b}} \mathbf{( \% )}$ & $\boldsymbol{M}_{\mathbf{n}}(\mathbf{g} / \mathbf{m o l})$ & $\boldsymbol{M}_{\mathbf{w}}(\mathbf{g} / \mathbf{m o l})$ & PDI \\
\hline MIBK-lignin & 40.31 & 100 & 767 & 1227 & 1.60 \\
MWL & 8.53 & 96.47 & 1940 & 3417 & 1.76 \\
\hline
\end{tabular}

a: the yield was calculated based on the AIL in the original biomass sample. ${ }^{\mathrm{b}}$ : the purity was obtained by subtracting the oligosaccharide fraction in the hydrolysate from composition analysis.

The weight-average $\left(M_{\mathrm{w}}\right)$, number-average $\left(M_{\mathrm{n}}\right)$ molecular weights, and the polydispersity index (PDI, $M_{\mathrm{W}} / M_{\mathrm{n}}$ ) of MIBK-lignin and MWL were also analyzed by gel permeation chromatography (GPC). According to Table 1, a significant decrease in both $M_{\mathrm{w}}$ and $M_{\mathrm{n}}$ of MIBK-lignin compared with MWL was presented. MWL is considered as the alternate to the native lignin; hence, it tends to remain in the form of a larger molecular weight $\left(1940 \mathrm{~g} / \mathrm{mol}\right.$ of $M_{\mathrm{n}}$ and $3417 \mathrm{~g} / \mathrm{mol}$ of $\left.M_{\mathrm{w}}\right)$ due to little damage to its chemical structures. After the pretreatment, however, the MIBK-lignin was decreased to 767 and 1227 in $M_{\mathrm{n}}$ and $M_{\mathrm{w}}$, respectively, indicating the linkages between lignin units, generally, the aryl ether linkages were broken. According to the previous results [21,26-28] showed in Table 2, the molecular 
weights of the extracted lignin from other systems and deep eutectic solvents (DESs), etc., still remained in several thousand grams per mole, which may ascribe to the condensation of the small lignin fractions by forming excess carbon-carbon bonds. This indicated, in some way, that less condensation occurred during the pretreatment of MIBK-lignin, which is considered as the result of the weak acidic conditions and the protection of the MIBK phase. The PDI describes the homogeneity of the lignin samples. Obviously, the PDI of MIBK-lignin (1.60) is smaller than that of MWL (1.76), demonstrating that the more homogeneous lignin was produced after the pretreatment. These characters indicate that the MIBK-lignin has great potential in high-value applications of lignin valorization.

Table 2. The molecular weights of extracted lignin reported in the literature.

\begin{tabular}{ccccc}
\hline & Conditions & $\boldsymbol{M}_{\mathbf{w}}(\mathrm{g} / \mathbf{m o l})$ & $\boldsymbol{M}_{\mathbf{n}} \mathbf{( g / \mathbf { m o l } )}$ & References \\
\hline ChCl-lactic acid & $140^{\circ} \mathrm{C}, 8 \mathrm{~h}$ & 1517 & 1329 & {$[34]$} \\
p-TsOH solution & $80^{\circ} \mathrm{C}, 20 \mathrm{~min}$ & 5400 & 2100 & {$[35]$} \\
ChCl-lactic acid & $145^{\circ} \mathrm{C}, 9 \mathrm{~h}$ & 1340 & - a & {$[30]$} \\
ChCl-oxalic acid & $130^{\circ} \mathrm{C}, 15 \mathrm{~min}(\mathrm{MW})$ & 2373 & 208 & {$[36]$} \\
ChCl-formic acid & $150{ }^{\circ} \mathrm{C}, 15 \mathrm{~min}(\mathrm{MW})$ & 5691 & 1647 & {$[36]$} \\
Ethanol/water- $\mathrm{FeCl}_{3}$ & $180^{\circ} \mathrm{C}, 1.5 \mathrm{~h}$ & 1642 & 956 & {$[37]$} \\
MIBK-water-FeCl & $180^{\circ} \mathrm{C}, 1 \mathrm{~h}$ & 1227 & 767 & This work \\
\hline \multicolumn{5}{c}{}
\end{tabular}

\subsection{Thermal Analysis}

The MIBK-lignin was compared with MWL in thermal properties by using a thermogravimetric (TGA) analyzer. The thermal analysis was carried out in the temperature range of 30 to $550{ }^{\circ} \mathrm{C}$, and the results are shown in Figure 1. As shown, the lignin degradation was recorded in two stages. The initial decomposition was done before the temperature approaches to $160^{\circ} \mathrm{C}$. The evaporation of water and the micromolecular lignin fraction are the main factors of the weight loss at this stage. From 160 to $550{ }^{\circ} \mathrm{C}$ was the main pyrolysis of the lignin. At this stage, both the MIBK-lignin and MWL showed a remarkable decrease in weight. From the DTG curves, it can be clearly seen that the degradation temperature ranges (from 161 to $550^{\circ} \mathrm{C}$ ) of the two classes of lignin were similar. However, the MIBK-lignin showed the maximum weight-loss rate at $356.83^{\circ} \mathrm{C}$, which is slightly superior to the MWL $\left(345^{\circ} \mathrm{C}\right)$. It indicates that the lignin was improved in thermostability after pretreatment and extraction. At $550{ }^{\circ} \mathrm{C}$, the residual mass of MIBK-lignin was $50.7 \%$, higher than that of the MWL $(39.8 \%)$. At this stage, the demethoxylation and re-condensation of volatile products mainly caused the formation of char, resulting in the weight stabilization. Based on the above-mentioned results, the MIBK-lignin obtained in this pretreatment endowed a better thermostability.

\subsection{FT-IR Analysis}

The FT-IR spectra of water generated MIBK-lignin were compared with MWL. As shown in Figure 2, the peak at $1514 \mathrm{~cm}^{-1}$ and $1426 \mathrm{~cm}^{-1}$ were typically related to aromatic skeletal vibrations indicating the spectra corresponded to lignin. The broad absorbance peak at $3421 \mathrm{~cm}^{-1}$ was attributed to the stretching vibrational bands of a hydroxyl group from alcohol and phenol. The increase in the intensity of double peaks of MIBK-lignin at $2936 \mathrm{~cm}^{-1}$ and $2840 \mathrm{~cm}^{-1}$ were C-H stretching in methyl and methylene groups respectively and possibly was the result of the elimination of functional groups on the side chain during the pretreatment. According to the previous work [38], the region of lower wavenumber, particularly the fingerprint region, can be used to distinguish lignin classification. From the MWL spectra, the most remarkable band at $1117 \mathrm{~cm}^{-1}$ was typical for $\mathrm{G}$ lignin units. Besides, the band at $1462 \mathrm{~cm}^{-1}$ is approximate to the reference band at $1514 \mathrm{~cm}^{-1}$; the peak at $1215 \mathrm{~cm}^{-1}$ was higher than that at $1270 \mathrm{~cm}^{-1}$; in the lower wavenumber range, there was a single band observed at $828 \mathrm{~cm}^{-1}$. Based on these features, the MWL can be identified as the type GS 3. However, as for the MIBK-lignin, some differences should be noticed in the fingerprint region. The reference band at 1514 
$\mathrm{cm}^{-1}$ shows more superior to the peak at $1462 \mathrm{~cm}^{-1}$, and in the lower wavenumber region, the double peaks which have been circled at $824 \mathrm{~cm}^{-1}$ and $850 \mathrm{~cm}^{-1}$ can be recognized. Moreover, shoulder peaks (have been circled) can be observed attaching to the bands at $1117 \mathrm{~cm}^{-1}$ and $1328 \mathrm{~cm}^{-1}$, respectively, which were related to the $\mathrm{H}$ units of lignin. According to the statements above, the variation on FT-IR spectra indicated the chemical structures of MIBK-lignin were converted remarkably, particularly the H-type might be formed. However, the details should be identified by further analysis.

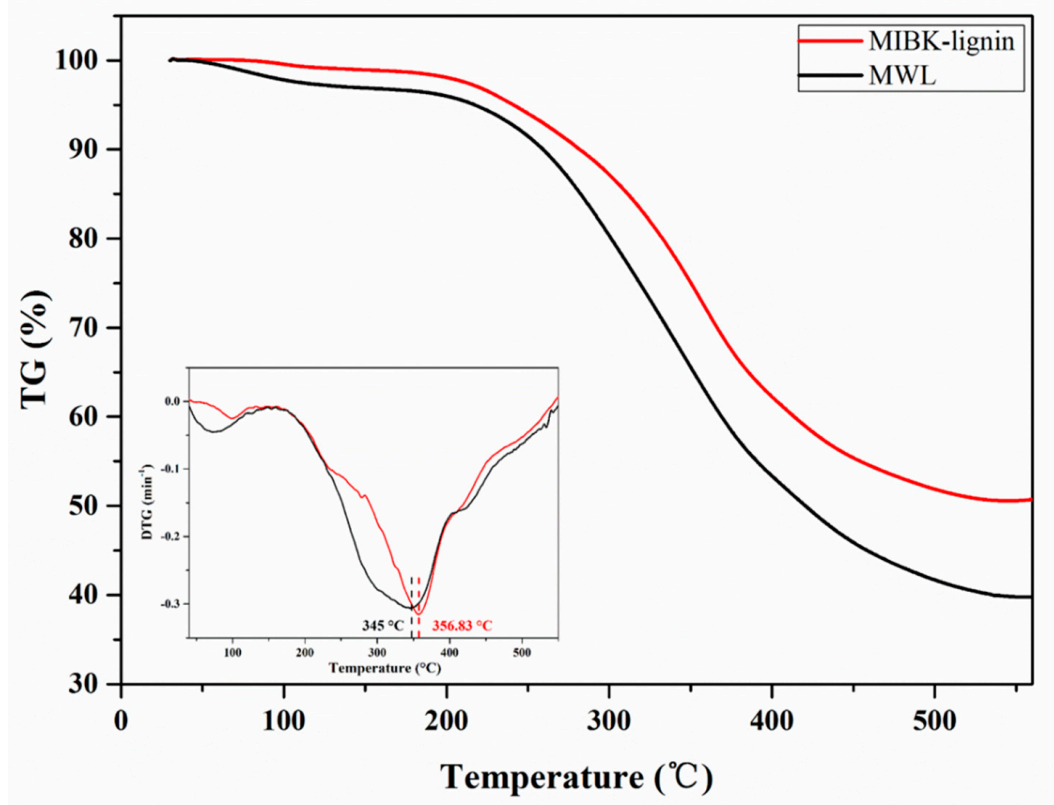

Figure 1. TGA and DTG curves of lignin fractions.

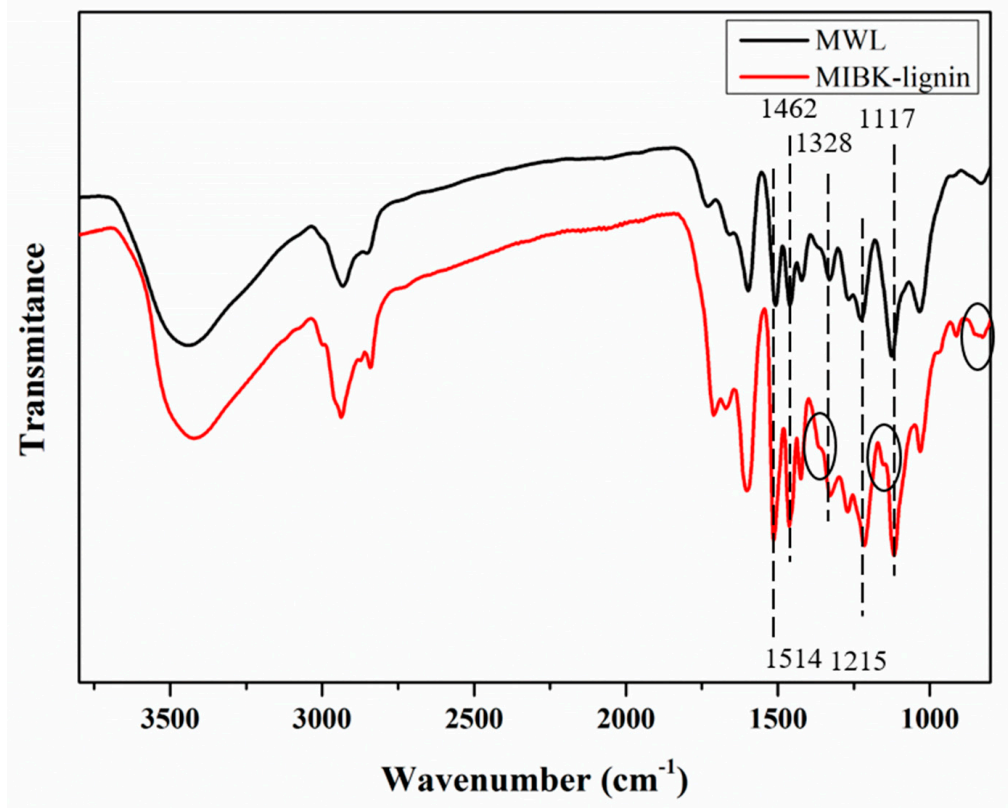

Figure 2. FT-IR spectra of lignin samples.

\subsection{D HSQC NMR Analysis}

2D HSQC NMR is one of the most important characterization methods for comprehending lignin chemical structures. MIBK-lignin was analyzed, compared with MWL, and the spectra of the lignin samples are shown in Figure 3. 

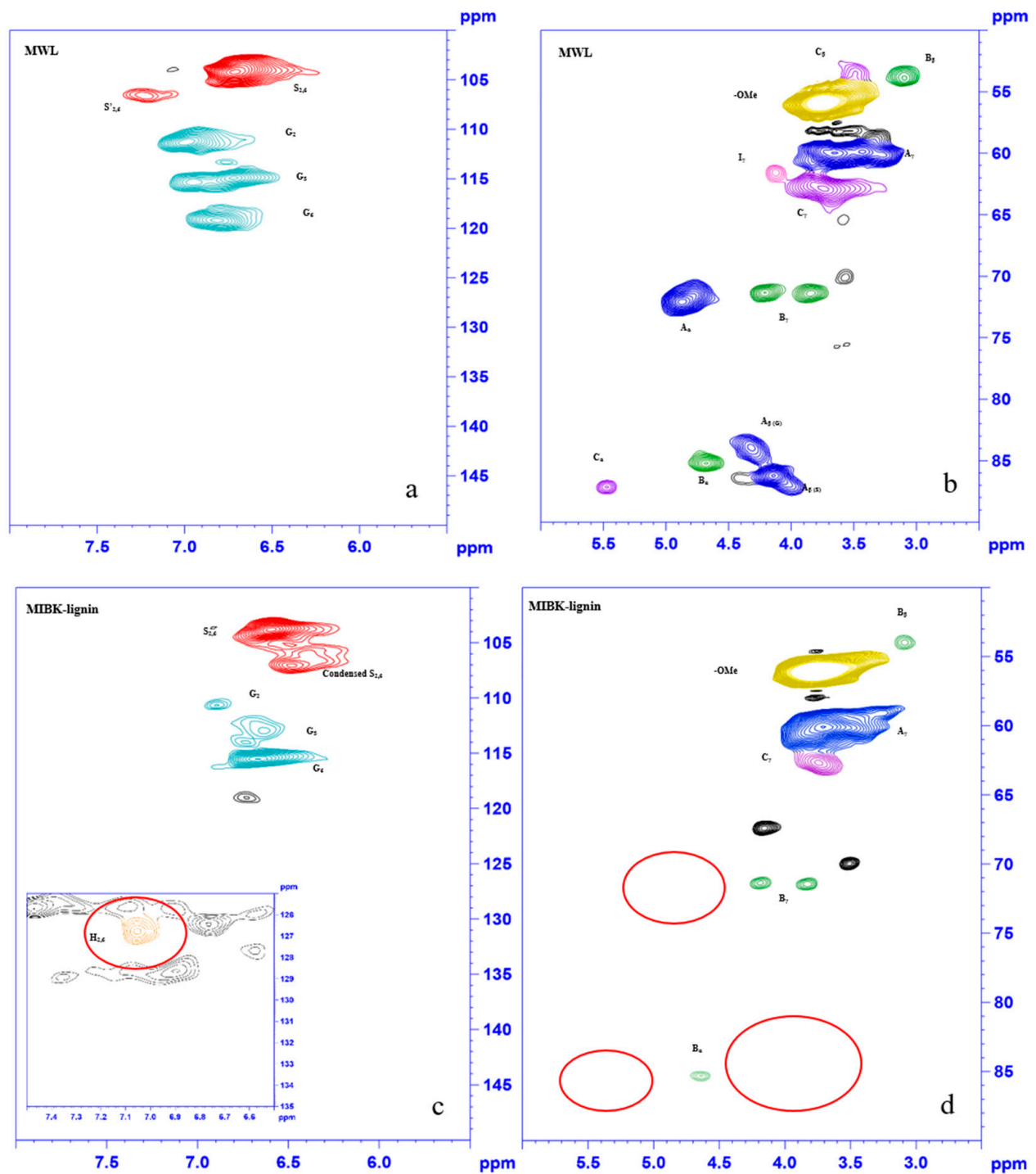

e<smiles>COc1cc(C(=O)O)cc(Oc2cc(C(C)(C)C)cc(OC)c2O)c1N</smiles>

S

'<smiles>CCc1ccc(C)c(OC(C)(C)c2cc(C)c(C)c(C)c2)c1</smiles>

A

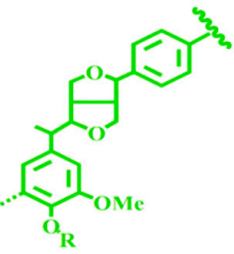

B<smiles>COc1cc(C(C)(C)C)cc(C)c1O</smiles>

G<smiles>Cc1cc(C)c(OCc2cccc(C(C)(C)C)c2)c(C)c1</smiles>

H<smiles>CCC1c2cc(C)cc(C)c2OC(c2cc(C)c(C)c(C)c2)C1CC</smiles>

C<smiles>CCOc1c(C)cc(/C=C/CO)cc1O</smiles>

I

Figure 3. 2D HSQC NMR spectra of MWL and MIBK-lignin. (a) the cross-peaks from aromatic ring region of MWL (b) the cross-peaks from side-chain region of MWL (c) the cross-peaks from aromatic ring region of MIBK-lignin (d) the cross-peaks from side-chain region of MIBK-lignin (e) the chemical structures of lignin units. 
The cross-peaks in Figure 3 were marked according to the cross-signal assignments published in the previous research [39]. The aromatic ring region $\left(\delta_{\mathrm{C}} / \delta_{\mathrm{H}} 150-100 / 5.5-8\right)$ expressed information about aromatic composition. Peaks from MWL corresponding to $S_{2,6}(104.11 / 6.64), S_{2,6}^{\prime}(106.59 / 7.23)$, $\mathrm{G}_{2}$ (111.22/6.93), $\mathrm{G}_{5}$ (114.47/6.72), and $\mathrm{G}_{6}(119.03 / 6.80)$ were clearly observed. The condensed $S$ type lignin peak was observed in MIBK-lignin, and the intensity of the $\mathrm{G}_{2}$ cross-signal was reduced sharply. Moreover, a weak signal assigned to $\mathrm{H}_{2,6}(127.11 / 7.17)$ (has been circled) appeared. These variations indicated that the $\mathrm{S}$ units condensed during the pretreatment and the type of lignin units changed, specifically, a new lignin unit, $\mathrm{H}$ unit was formed, which was coincident with the conclusion from FT-IR analysis. The region $\left(\delta_{\mathrm{C}} / \delta_{\mathrm{H}} 90-50 / 6-2.5\right)$ corresponding to the side-chain of the lignin, revealed the variation of lignin interunit linkages during the pretreatment. Figure $3 b$ showed the three main lignin interunit linkages, aryl ether linkage (A), resinols (B), and phenylcoumarans (C) in original Eucalyptus sample, and these cross-signals were distinguished at $\delta_{\mathrm{C}} / \delta_{\mathrm{H}} 71.8142 / 4.8280\left(\mathrm{~A}_{\alpha}\right), 85.1310 / 4.6798\left(\mathrm{~B}_{\alpha}\right)$, and 87.1398/5.4720 $\left(\mathrm{C}_{\alpha}\right)$, respectively. However, in the MIBK-lignin spectra, the signals attributing to aryl ether linkage and phenylcoumarans at $\delta_{\mathrm{C}} / \delta_{\mathrm{H}} 71.8142 / 4.8280$ and $87.1398 / 5.4720$ (have been circled) were disappeared, while the peak at $\delta_{\mathrm{C}} / \delta_{\mathrm{H}} 85.1310 / 4.6798\left(\mathrm{~B}_{\alpha}\right)$ were retained. The percentage of the several classes of lignin interunit linkages were also calculated in detail according to the previous study [5] and showed in Table 3. According to the table, most lignin units of the MWL samples were linked by aryl ether linkage, accounting for $80.03 \%$, followed by the resinols $(15.90 \%)$ with a slight of phenylcoumarans $(4.06 \%)$. After the pretreatment, only the resinols remained. Additionally, S/G ratio increased sharply, which resulted from the severe degradation of G-type lignin. Based on the above, the aryl ether linkage and phenylcoumarans were broken selectively during the pretreatment, causing the significant decrease of molecular weight; however, the resinols were more resistant. G-type lignin is more sensitive than the S-type, and after the pretreatment, H-type lignin was formed, indicating the occurrence of demethoxylation reaction on high temperature [25]. The results were coincident with the FT-IR and GPC analysis.

Table 3. Percentage of lignin interunit linkages and units in the samples.

\begin{tabular}{ccccc}
\hline Samples & Aryl Ether (A) & Resinols (B) & Phenylcoumarans (C) & S/G Ratio \\
\hline MWL & 80.03 & 15.90 & 4.06 & 1.13 \\
MIBK-lignin & $-{ }^{a}$ & 100 & - & 9.11 \\
\hline \multicolumn{5}{c}{ a: "-" means not detected. $^{c}$}
\end{tabular}

\subsection{Morphological Observations}

The MIBK-lignin was identified as nano-particles by atomic force microscopy (AFM), showed in Figure 4. The freeze-dried MIBK-lignin was firstly dispersed in deionized water at a concentration of $2 \mathrm{wt} \%$ followed by ten-minute ultrasound treatment. The lignin nano-particles in upper suspension liquid was observed on a clean mica surface. Due to precipitation, filtration and freeze-drying, the agglomerations of the lignin nano-particles can be observed. Despite this, plenty of homogeneous lignin nano-particles were still clearly seen in Figure $4 a$. As shown in Figure $4 b$, the profiles of samples 1 and 2, respectively, corresponding to lines 1 and 2 in Figure 4a precisely described the particle diameters. The diameter of the lighter single particle named 1 was $69 \mathrm{~nm}$, and the darker double particles were 49 and $59 \mathrm{~nm}$, respectively. The similar diameters between the two samples indicated that both the lighter and the dark particles are shown in the image were lignin nano-particles (our product), only they are not in the same layer, consequently showing the difference in height. From the TEM image (Figure 4c), the nano-particles can be observed more clearly, appearing as spheres with diameters about $100 \mathrm{~nm}$. However, some agglomerations still can be seen. Dynamic light scattering (DLS) was applied subsequently for the more accurate particle diameters distribution (Figure 4d). The particle diameters ranged from 70.89 to 307.6 , with a mode number of $127.5 \mathrm{~nm}$, and the average diameter of the measured samples was $131.8 \mathrm{~nm}$, with the PDI of 0.149 . The combined analyses of AFM, TEM, and DLS visually confirmed that a series of homogeneous lignin nano-particles could 
easily be obtained by the Lewis acid ferric trichloride hydrolysis modified organosolv pretreatment. Based on the results discussed above, our lignin nano-particles which are directly separated from biomass exhibit great potential in producing high functional and valuable materials applying in wide fields, such as the addition for functional membrane and natural rubber composites, or lignin-based nano-capsules for pharmaceutical applications [40-43].
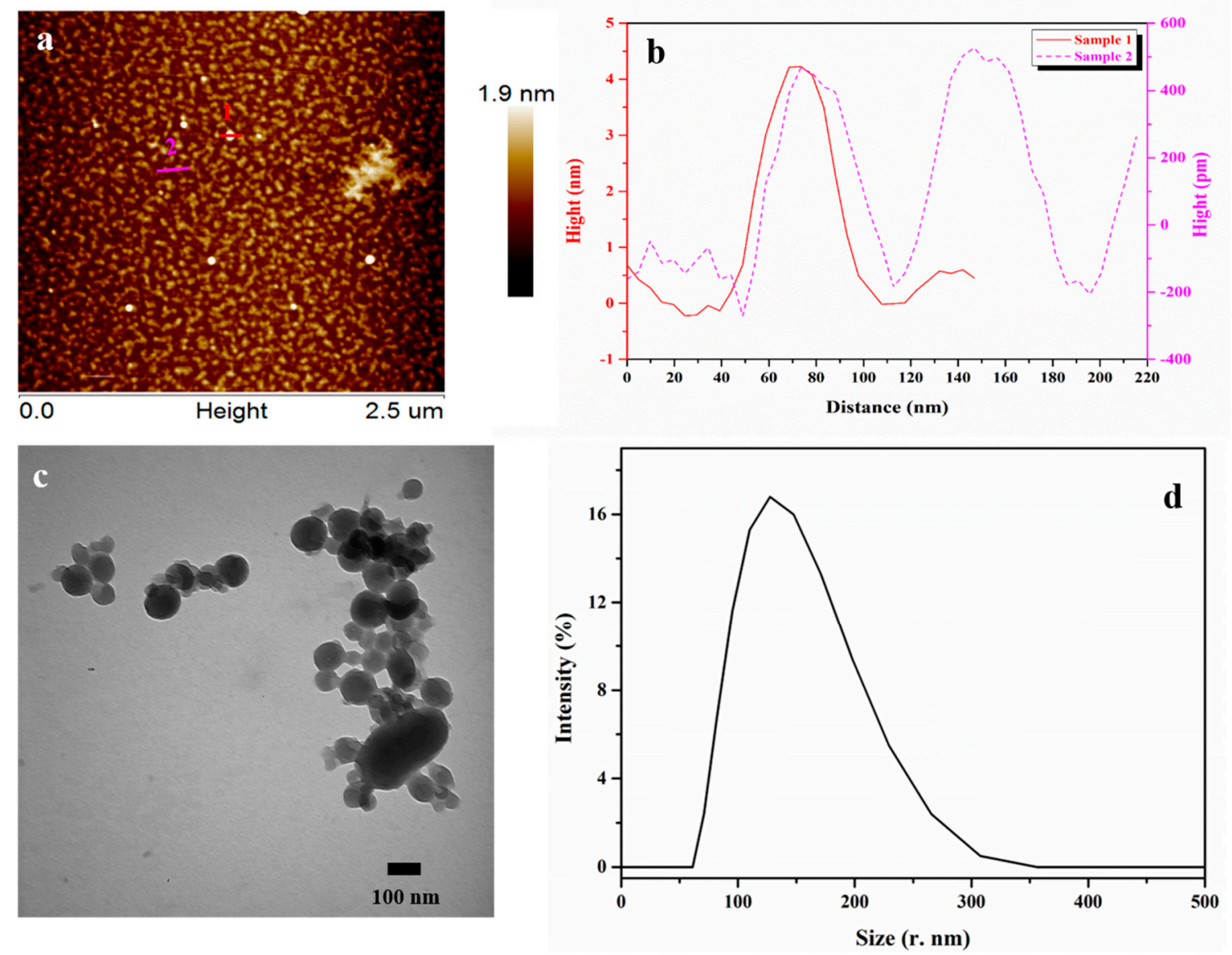

Figure 4. Morphological observation of MIBK-lignin. (a) AFM image of MIBK-lignin (b) the profiles of samples (c) TEM image of MIBK-lignin (d) particle diameters distribution analyzed by DLS. (r.: diameter)

\section{Conclusions}

This work proposed a simple biorefinery process, particularly to obtain the lignin nano-particles from Eucalyptus biomass by the Lewis acid ferric trichloride hydrolysis modified organosolv pretreatment with MIBK. Under the conditions $\left(180{ }^{\circ} \mathrm{C}, 1 \mathrm{~h}\right), 40.13 \%$ of the acid-insoluble lignin in original biomass can be obtained with a high purity of $100 \%$ and a low molecular weight of $767\left(M_{n}\right)$. The obtained lignin sample was also improved in homogeneity and thermostability characterized by GPC and TGA, respectively. According to FT-IR analysis, the chemical structures of the extracted lignin were converted remarkably as compared to $\mathrm{MWL}$, particularly the $\mathrm{H}$-type unit might be formed. 2D NMR spectroscopy analysis further confirmed the conversion in detail. The aryl ether linkage and phenylcoumarans were broken severely; however, the resinols is more resistant. Besides, G-type lignin is more sensitive to degradation, than the S-type, and after the pretreatment, H-type lignin was formed, indicating the occurrence of demethoxylation reaction at high temperature. Moreover, the lignin nano-particles were identified visually by AFM and TEM images. The DLS was also applied for the more accurate particle diameters distribution and showed that the average diameter of the measured samples was $131.8 \mathrm{~nm}$, with the PDI of 0.149. Results indicate that MIBK-lignin nano-particles have great potential in producing high functional and valuable materials with wide field applications. 
Author Contributions: Conceptualization, Q.Z.; methodology, H.L. and Z.G.; software, Q.Z.; validation, F.X.; formal analysis, Q.Z., H.L. and Z.G.; investigation, Q.Z.; resources, F.X.; data curation, Q.Z.; writing-original draft preparation, Q.Z.; writing—review and editing, Q.Z. and F.X.; visualization, Q.Z.; supervision, F.X.; project administration, F.X.; funding acquisition, F.X. All authors have read and agreed to the published version of the manuscript.

Funding: This research was funded by [World-Class Discipline Construction and Characteristic Development Guidance Funds for Beijing Forestry University] grant number [2019XKJS0330].

Conflicts of Interest: The authors declare no conflict of interest.

\section{References}

1. Guo, Z.; Zhang, Q.; You, T.; Zhang, X.; Xu, F.; Wu, Y. Short-time deep eutectic solvent pretreatment for enhanced enzymatic saccharification and lignin valorization. Green Chem. 2019, 21, 3099-3108. [CrossRef]

2. Rinaldi, R.; Jastrzebski, R.; Clough, M.T.; Ralph, J.; Kennema, M.; Bruijnincx, P.C.; Weckhuysen, B.M. Paving the way for lignin valorisation: Recent advances in bioengineering, biorefining and catalysis. Angew. Chem. Int. Ed. Engl. 2016, 55, 8164-8215. [CrossRef] [PubMed]

3. De France, K.J.; Hoare, T.; Cranston, E.D. Review of hydrogels and aerogels containing nanocellulose. Chem. Mater. 2017, 29, 4609-4631. [CrossRef]

4. Ragauskas, A.J.; Beckham, G.T.; Biddy, M.J.; Chandra, R.; Chen, F.; Davis, M.F.; Davison, B.H.; Dixon, R.A.; Gilna, P.; Keller, M.; et al. Lignin valorization: Improving lignin processing in the biorefinery. Science 2014, 344, 1246843. [CrossRef]

5. You, T.; Zhang, L.; Guo, S.; Shao, L.; Xu, F. Unraveling the Structural Modifications in Lignin of Arundo donax Linn. during Acid-Enhanced Ionic Liquid Pretreatment. J. Agric. Food Chem. 2015, 63, 10747-10756. [CrossRef] [PubMed]

6. Shuai, L.; Amiri, M.T.; Questell-Santiago, Y.M.; Héroguel, F.; Li, Y.; Kim, H.; Meilan, R.; Chapple, C.; Ralph, J.; Luterbacher, J.S. Formaldehyde stabilization facilitates lignin monomer production during biomass depolymerization. Science 2016, 354, 329-333. [CrossRef]

7. $\quad$ Figueirêdo, M.B.; Deuss, P.J.; Venderbosch, R.H.; Heeres, H.J. Valorization of Pyrolysis Liquids: Ozonation of the Pyrolytic Lignin Fraction and Model Components. ACS Sustain. Chem. Eng. 2019, 7, 4755-4765. [CrossRef]

8. Schutyser, W.; Renders, T.; Van den Bosch, S.; Koelewijn, S.F.; Beckham, G.T.; Sels, B.F. Chemicals from lignin: An interplay of lignocellulose fractionation, depolymerisation, and upgrading. Chem. Soc. Rev. 2018, 47, 852-908. [CrossRef]

9. Nilsson, T.Y.; Wagner, M.; Inganas, O. Lignin modification for biopolymer/conjugated polymer hybrids as renewable energy storage materials. ChemSusChem 2015, 8, 4081-4085. [CrossRef]

10. Sun, S.; Sun, S.; Cao, X.; Sun, R. The role of pretreatment in improving the enzymatic hydrolysis of lignocellulosic materials. Bioresour. Technol. 2016, 199, 49-58. [CrossRef]

11. Domínguez de María, P. Recent trends in (ligno) cellulose dissolution using neoteric solvents: Switchable, distillable and bio-based ionic liquids. J. Chem. Technol. Biotechnol. 2014, 89, 11-18. [CrossRef]

12. Zdanowicz, M.; Wilpiszewska, K.; Spychaj, T. Deep eutectic solvents for polysaccharides processing. A review. Carbohydr. Polym. 2018, 200, 361-380. [CrossRef] [PubMed]

13. Zhang, K.; Pei, Z.; Wang, D. Organic solvent pretreatment of lignocellulosic biomass for biofuels and biochemicals: A review. Bioresour. Technol. 2016, 199, 21-33. [CrossRef] [PubMed]

14. Zhao, X.; Cheng, K.; Liu, D. Organosolv pretreatment of lignocellulosic biomass for enzymatic hydrolysis. Appl. Microbiol. Biotechnol. 2009, 82, 815. [CrossRef]

15. Taherzadeh, M.J.; Karimi, K. Pretreatment of lignocellulosic wastes to improve ethanol and biogas production: A review. Int. J. Mol. Sci. 2008, 9, 1621-1651. [CrossRef]

16. Bozell, J.J.; Black, S.K.; Myers, M.; Cahill, D.; Miller, W.P.; Park, S. Solvent fractionation of renewable woody feedstocks: Organosolv generation of biorefinery process streams for the production of biobased chemicals. Biomass Bioenergy 2011, 35, 4197-4208. [CrossRef]

17. Sannigrahi, P.; Ragauskas, A.J.; Miller, S.J. Lignin structural modifications resulting from ethanol organosolv treatment of loblolly pine. Energy Fuels 2010, 24, 683-689. [CrossRef]

18. Brosse, N.; Sannigrahi, P.; Ragauskas, A. Pretreatment of Miscanthus $x$ giganteus Using the Ethanol Organosolv Process for Ethanol Production. Ind. Eng. Chem. Res. 2009, 48, 8328-8334. [CrossRef] 
19. El Hage, R.; Brosse, N.; Chrusciel, L.; Sanchez, C.; Sannigrahi, P.; Ragauskas, A. Characterization of milled wood lignin and ethanol organosolv lignin from miscanthus. Polym. Degrad. Stab. 2009, 94, 1632-1638. [CrossRef]

20. Cybulska, I.; Brudecki, G.; Rosentrater, K.; Julson, J.L.; Lei, H. Comparative study of organosolv lignin extracted from prairie cordgrass, switchgrass and corn stover. Bioresour. Technol. 2012, 118, 30-36. [CrossRef]

21. Klamrassamee, T.; Tana, T.; Laosiripojana, N.; Moghaddam, L.; Zhang, Z.; Rencoret, J.; Gutierrez, A.; del Rio, J.C.; Doherty, W.O.S. Effects of an alkali-acid purification process on the characteristics of eucalyptus lignin fractionated from a MIBK-based organosolv process. RSC Adv. 2016, 6, 92638-92647. [CrossRef]

22. Bozell, J.J.; O'Lenick, C.J.; Warwick, S. Biomass Fractionation for the Biorefinery: Heteronuclear Multiple Quantum Coherence-Nuclear Magnetic Resonance Investigation of Lignin Isolated from Solvent Fractionation of Switchgrass. J. Agric. Food Chem. 2011, 59, 9232-9242. [CrossRef] [PubMed]

23. Singh, R.; Krishna, B.B.; Kumar, J.; Bhaskar, T. Opportunities for utilization of non-conventional energy sources for biomass pretreatment. Bioresour. Technol. 2016, 199, 398-407. [CrossRef]

24. Xu, J.; Xiong, P.; He, B. Advances in improving the performance of cellulase in ionic liquids for lignocellulose biorefinery. Bioresour. Technol. 2016, 200, 961-970. [CrossRef]

25. Wen, J.-L.; Yuan, T.-Q.; Sun, S.-L.; Xu, F.; Sun, R.-C. Understanding the chemical transformations of lignin during ionic liquid pretreatment. Green Chem. 2014, 16, 181-190. [CrossRef]

26. You, T.; Shao, L.; Wang, R.; Zhang, L.; Xu, F. Facile isothermal solid acid catalyzed ionic liquid pretreatments to enhance the combined sugars production from Arundo donax Linn. Biotechnol. Biofuels 2016, 9, 177. [CrossRef]

27. Varanasi, P.; Singh, P.; Arora, R.; Adams, P.D.; Auer, M.; Simmons, B.A.; Singh, S. Understanding changes in lignin of Panicum virgatum and Eucalyptus globulus as a function of ionic liquid pretreatment. Bioresour. Technol. 2012, 126, 156-161. [CrossRef]

28. Li, T.; Lyu, G.; Liu, Y.; Lou, R.; Lucia, L.A.; Yang, G.; Chen, J.; Saeed, H.A.M. Deep eutectic solvents (DESs) for the isolation of willow lignin (salix matsudana cv. zhuliu). Int. J. Mol. Sci. 2017, 18, 2266. [CrossRef]

29. Chen, Z.; Wan, C. Ultrafast fractionation of lignocellulosic biomass by microwave-assisted deep eutectic solvent pretreatment. Bioresour. Technol. 2018, 250, 532-537. [CrossRef]

30. Alvarez-Vasco, C.; Ma, R.; Quintero, M.; Guo, M.; Geleynse, S.; Ramasamy, K.K.; Wolcott, M.; Zhang, X. Unique low-molecular-weight lignin with high purity extracted from wood by deep eutectic solvents (DES): A source of lignin for valorization. Green Chem. 2016, 18, 5133-5141. [CrossRef]

31. Zhang, C.W.; Xia, S.Q.; Ma, P.S. Facile pretreatment of lignocellulosic biomass using deep eutectic solvents. Bioresour. Technol. 2016, 219, 1-5. [CrossRef] [PubMed]

32. Liu, Y.; Chen, W.; Xia, Q.; Guo, B.; Wang, Q.; Liu, S.; Liu, Y.; Li, J.; Yu, H. Efficient Cleavage of Lignin-Carbohydrate Complexes and Ultrafast Extraction of Lignin Oligomers from Wood Biomass by Microwave-Assisted Treatment with Deep Eutectic Solvent. ChemSusChem 2017, 10, 1692-1700. [CrossRef] [PubMed]

33. Sluiter, A.; Hames, B.; Ruiz, R.; Scarlata, C.; Sluiter, J.; Templeton, D.; Crocker, D. Determination of structural carbohydrates and lignin in biomass. Lab. Anal. Proced. 2008, 1617, 1-16.

34. Liu, D.; Yan, X.; Zhuo, S.; Si, M.; Liu, M.; Wang, S.; Ren, L.; Chai, L.; Shi, Y. Pandoraea sp. B-6 assists the deep eutectic solvent pretreatment of rice straw via promoting lignin depolymerization. Bioresour. Technol. 2018, 257, 62-68. [CrossRef] [PubMed]

35. Chen, L.; Dou, J.; Ma, Q.; Li, N.; Wu, R.; Bian, H.; Yelle, D.J.; Vuorinen, T.; Fu, S.; Pan, X.; et al. Rapid and near-complete dissolution of wood lignin at $\leq 80{ }^{\circ} \mathrm{C}$ by a recyclable acid hydrotrope. Sci. Adv. 2017, 3, e1701735. [CrossRef] [PubMed]

36. Muley, P.D.; Mobley, J.K.; Tong, X.; Novak, B.; Stevens, J.; Moldovan, D.; Shi, J.; Boldor, D. Rapid microwave-assisted biomass delignification and lignin depolymerization in deep eutectic solvents. Energy Convers. Manag. 2019, 196, 1080-1088. [CrossRef]

37. Koumba-Yoya, G.; Stevanovic, T. Rapid microwave-assisted biomass delignification and lignin depolymerization in deep eutectic solvents. ChemistrySelect 2016, 1, 6562-6570. [CrossRef]

38. Faix, O. Classification of lignins from different botanical origins by FT-IR spectroscopy. Holzforschung-Int. J. Biol. Chem. Phys. Technol. Wood 1991, 45, 21-28. [CrossRef] 
39. Prinsen, P.; Gutiérrez, A.; Rencoret, J.; Nieto, L.; Jiménez-Barbero, J.; Burnet, A.; Petit-Conil, M.; Colodette, J.L.; Martínez, Á.T.; del Río, J.C. Morphological characteristics and composition of lipophilic extractives and lignin in Brazilian woods from different eucalypt hybrids. Ind. Crops Prod. 2012, 36, 572-583. [CrossRef]

40. Jiang, C.; He, H.; Jiang, H.; Ma, L.; Jia, D.M. Nano-lignin filled natural rubber composites: Preparation and characterization. Express Polym. Lett. 2013, 7, 480-493. [CrossRef]

41. Duval, A.; Lawoko, M. A review on lignin-based polymeric, micro-and nano-structured materials. React. Funct. Polym. 2014, 85, 78-96. [CrossRef]

42. Frangville, C.; Rutkevičius, M.; Richter, A.P.; Velev, O.D.; Stoyanov, S.D.; Paunov, V.N. Fabrication of environmentally biodegradable lignin nanoparticles. ChemPhysChem 2012, 13, 4235-4243. [CrossRef] [PubMed]

43. Tortora, M.; Cavalieri, F.; Mosesso, P.; Ciaffardini, F.; Melone, F.; Crestini, C. Ultrasound driven assembly of lignin into microcapsules for storage and delivery of hydrophobic molecules. Biomacromolecules 2014, 15, 1634-1643. [CrossRef] [PubMed]

(C) 2020 by the authors. Licensee MDPI, Basel, Switzerland. This article is an open access article distributed under the terms and conditions of the Creative Commons Attribution (CC BY) license (http://creativecommons.org/licenses/by/4.0/). 